\title{
Learning Anytime, Anywhere: Benefits and Challenges of M-Learning through the Cloud
}

\author{
Samar Alamri ${ }^{1}$, Dr. Maram Meccawy ${ }^{2}$, Bushra Khoja ${ }^{3}$, Hasnaa Bakhribah ${ }^{4}$ \\ Information System, KAU, Jeddah, Saudi Arabia ${ }^{1,2,3,4}$
}

\begin{abstract}
With mobile learning (m-learning), the learner only needs to have a smartphone and access to the internet; with that, they can access all the resources they need to study without having to carry books around with them. Some of the advantages of m-learning include areduction in cost, elasticity, flexibility and collaborative learning. On the flipside, this method of learning has its drawbacks that include screen size and the battery life of the smart phone, distractions during the learning process, and internet charges. Since the advantages are on the higher side, it is important that the mobile learning be adopted by educational instotuties and training centres to enhance the quality and accessibility of learning. The introduction of new technology in m-learning such as ambient intelligence, location-based learning, and learning implants implies that mobile learning has a bright future. This paper provides an overview of $\mathrm{m}$ learning via the cloud computing technology and introduces a mobile application that teaches programming to young children as an example of this type of learning.
\end{abstract}

Keywords: Cloud computing, Mobile learning (m-learning), Android Application, Programming, e-Learning.

\section{INTRODUCTION}

Technology influences all aspects of human lives, including education, training, health, tourism, to name but a few. Cloud computing and mobile learning are two innovations in the technological realm that have changed how individuals learn, store and access data. Cloud computing could be described a service that allows for storage and access of data and programs remotely over the internet [9]. This service allows multiple individuals to access and manipulate programs as they wish, together with the ability to store as much data as they can over the internet. Certain technological companies usually offer the service. They include Google, Apple, Amazon, and Microsoft, among many other providers.

Cloud computing is categorized into three broad categories: infrastructure as a service (IaaS), platform as a service (PaaS) and software as service (SaaS) [3]. In platform as a service, a consumer who most likely is a corporate company, is given the ability to develop its custom web development tool by the service provider, which can be accessed by its employees. The service provider will most likely host the software after the system been developed. This software allows the employees of the company to log in using provided user names and passwords. The company will have control over manipulating the data entered in by its employees. Examples of PaaS providers are Google app engine and Amazon Elastic Beanstalk [9].

Infrastructure as a service involves a situation where the service provider offers the client a virtual storage together with access to a virtual server. The service provider manages the actual server or the hardware components of the server. The clients share the server as if they have full control of it. The clients manage their websites from the same server and have the ability to store as much information as they can in the virtual storage.

Software as a service allows the client to use software applications provided by the service provider over the internet. A good example is Microsoft Office online. The client can access these software applications remotely from any location or hardware capable of accessing the internet. The client is, therefore, free from the responsibility of handling this software [6]. These are the main uses of cloud computing tools and from the above information, it couldbe concluded that cloud computing is very much necessary in this age and time.

Education is a vital sector in any country that strives to improve its labor force and for general economic development. It is, therefore, necessary that new ways of circulating knowledge are developed to keep up the pace with the technological advances in the current world.. Mobile technologies [14] as well as cloud computing are paving the road towards achieving this goal. Learning is no longer only taking place in the classroom as learners are constantly on the move. Mobile learning involves learning across multiple contexts, through social and content interactions, using personal electronic devices such as mobile phones and tablets. It gained popularity as it provides convenience and flexibility since mobile learning can be accessed anywhere, at the exact moment learning is required. It provides learning on demand and allows users more control over their learning process.

M-Learning enables the learner and the teacher to share knowledge through devices such as smartphones, tablets, and personal computers. This has revolutionized how learning takes place since students can now learn from any location and not only in the confines of the classroom. Teachers can prepare and access digital content and assessment tests that they send to students over the internet. This has improved how students access information. The only hardware that the 
student needs to have is a smartphone or tablet [3]. This has greatly broadened the target population of students that can access the digital content and use it in their studies since almost all school going student have access to a smartphone or tablet.

\section{HOW CLOUD COMPUTING AND M-LEARNING ENHANCE E-LEARNING}

Cloud computing is designed to offer stored information to multiple users remotely without the need to deal with the hardware problems associated with maintaining a server. It also allows the users to pay for what they want to use at that time. This feature makes cloudcomputing perfect for mobile learning. Individual tutors can upload digital learning resources to a cloud-based system, and students will be able to accessit from the same system. Learning institutions with the need to provide their learners with learning materials whenever and wherever they want. They can create a cloudbased application that will allow its students to log on and access digital learning resources. This system must support mobile devices such as smartphones so as not to lock out anyone from accessing its services [2]. The information can be arranged in such a way that the student can select the subject of choice then the topic of choice and at the end of the topic, they have an assessment object. Learning resources offered should include and is not limited to text-based documents, video tutorials and audio files of lectures.

Learners can use two means to access the stored data on the cloud-based system. One, they can have a custom-made website where students can search and log in. Once they give the correct password and username, they can freely access the learning resources. Another way involves the users downloading and installing an application on their smartphone. With the app installed, they can easily connect to a Wi-Fi hotspot and access learning materials.

The use of cloud computing in online learning is limitless, but first, teachers and students need tobe trained on how to use online teaching and learning resources effectively. Both the students and tutors will be ready to reap the fruits of cloud computing fully. The online cloud computing platform can be designedin a way that gives the student added learning experience. Tutors can upload videos of lectures that will be viewed and downloaded by numerous students who could then jot down notes at their own pace unlike in a traditional classrooms [1]. The learners can share the ideas with professionals from different fields, get reference materials and share with other students in virtual classrooms. Virtual laboratories can also be included in the cloud-based system. This inclusion will enable students view and conduct experiments online. It will also help the learner understand and grasp taught contents better. Below are the main benefits that cloud computing provides to e-learning followed by the challenges it faces in this area.

\section{A. Opportunities}

Cloud-based learning has a variety of advantages compared to traditional methods of learning. In the traditional setup, both students and tutors have to deal with challenges that include the need to travel long distances to classrooms, having to deal with computer hardware breakdowns, the general monotony of classroom learning and lack of personalized attention. Below are some of the benefits of cloud-based teaching platforms.

1) Cost reduction: setting up a cloud-based learning application frees learning institutions of the cost of maintaining servers, handling server breakdowns, payment of extra personnel for system maintenance and the cost of movement for tutors from one state to another [4]. They are also relieved of the need to continually maintain and update new software's due to the ever-changing technological world. The saved funds would be channelled to other projects to improve overall learning.

2) Elasticity: when dealing with cloud-based servers, there is no limit on the number of students that a single tutor can reach tutor. This platform supports live video streaming to thousands of students at a time together with the ability to have some personalized chat [12]. All these can take place since powerful remote servers that can sustain several students at any time hence eliminating the need to have a physical classroom support the cloud computing system.

3) Flexibility: cloud-based mobile learning allows the student to choose where and when to log in and access the necessary learning materials. The students are therefore at an advantage since they decide to learn at their own comfort and convenience. The resources uploaded on cloud-based systems are usually of varied formats to cater for the differences in learner preference. The student can choose whether to watch a tutorial or read notes.

4) Collaborative learning:Studying through cloud-based mobile learning tools provides the learner with an avenue to discuss with other learners and share ideas on the online platform. This gives the learners a chance to broaden their thinking and be able to understand concepts better.

5) Highly engaging: due to the varied number of resources used in mobile learning, students are always engrossed in the learning process hence there will be few dropouts, if any [7].

6) Higher retention

Mobile learning is not only fun but also very enriching in terms of knowledge. Tutors create shorter lessons, and the information is usually organized in a summarized form that student can understand and apply to their normal lives. This boosts knowledge retention levels for the students taking online education [12]. 
Lastly, mobile learning can continue even when one is offline. This is due to the fact that the learners are given an opportunity to download learning materials at any time [5]. They can still refer from the downloaded tutorials and notes when they are offline thus making mobile learning be very flexible. Provided the learning providers allow this feature.

\section{B. Challenges}

1) Costly internet charges

The cost of internet connections in most parts of the world is expensive consequently limiting the number of people who can access this service. Mobile learning requires one to have a constant data plan to facilitate video conferencing on the phone, downloading notes, books and viewing tutorials. Due to the ever-soaring internet connection rates, many might be students are locked out.

\section{2) Acceptability}

As much as almost all students have smartphones today, most of them prefer to use their phones for social purposes such as listening to music, online chatting and social networking and not to learn [10]. Therefore, unless the society is ready to take advantage of the benefits of mobile learning, it will remain far-reaching.

\section{3) Complexity}

On the side of the tutors, it may be a challenge to manage a website and at the same time performs other tasks such as grading assessments and preparing for lessons. It will therefore be a burdento them since they are also expected to provide personalized service to the students.

\section{4) Security}

Mobile learning allows for learning to take place outside the classroom where teacher can supervise the learning process. Therefore, young learnerswill be exposed to the Webwhere there might face some dangers which may impede the learning process rather than encourage [13]. The students willneed much guidance when using the Internet. In addition, if the learners' data alongside the learning content are stored online, they face risks of being hacked or manipulated.

5) Technical challenges: these include battery life of the phone, which may cause a temporary loss of connectivity if oneis far from the grid. The phone screen size may also be a problem especially if it is small. This may lead to eyesight problems because of eye straining. Distractions that come with using the phone for learning include calls and texts that affect the concentration span of an individual [10]. The learning environment also affects how things are understood and the concentration. For instance, training while one is driving or a construction site are not conducive settings for learning. The bandwidth required for nonstop streaming is also a problem; for m-learning to be fast and short, it needs excellent streaming and people in areas without that connectivity are disadvantaged. The number of file formats supported is also important; the device should be able to support the required files. Phone memory should be sufficient to enable downloading of materials needed, and if this is not considered, it is a challenge to m-learning [10].

\section{THE LITTLE PROGRAMMER: AN M-LEARNING APPLICATION}

The little Programmer is a mobile application for mobile devices (phones and tablets)that introduces programming to young Arab children (8-12 years) outside the classroom settings. It explains these concepts using videos, animations and simple matching puzzles.It makes use of the many opportunities mentioned earlier that cloud computing offers to elearning combined with the capabilities provided by m-learning.It has also carefully considered the known challenges of both technologies (cloud computing and m-Learning) while designing the GUI and the users' interactions. For instance, the screen size and the capacity of device's memory are much smaller in mobile devices. In addition, constant internet access might not always be granted for children. In addition, some teachers and parents raised concerns about allowing young learners to freely access the internet. Therefore, learning objects are stored in two different location, each to serve a certain purpose. To allow for offline access and learning, most of the learning objectsare stored on the user's device using Android realm server, while the educational videos, due to their size, are stored on YouTube's server. Hence, they could only be accessed online. YouTube provides a Public, Software-as-a-Service Cloud. Public verses Private in terms of accessing the videos is a matter of their owner.The application has been developed has been implemented for Android devices only following Agile-D-Mobile methodology,which takes in consideration the rapid change that happens in software development, support small releases, risk handling, user involvement and continuous updating. The application's interface is shown in figure (1) with indications to where the learning objects are stored.

Initial testing showed that using the application got the young learners excited about computer programming and a good understanding of the knowledge presented while using it. The flexibility of m-learning provide by the application allowed those young learner to be connected to learning content outside the classroom. It provide a learning on the go experience, which kept the learning engaged and interested in learning. 


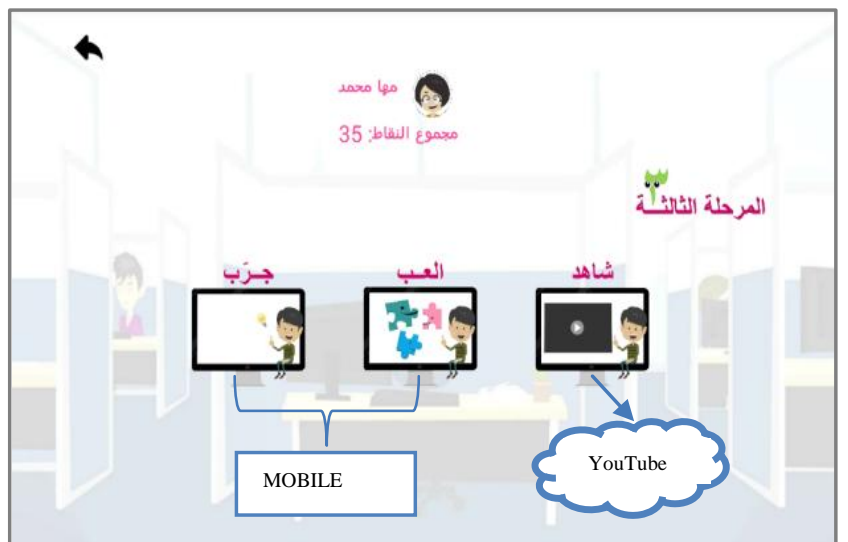

Fig1.The Little Programmer Interface on an Android Tablet

\section{FUTURE OF M-LEARNING}

M-Learning is expected to continue to flourish and advance in the coming future. In addition to better utilization of the cloud computing technology, the following trends will dominated the seen in this branch of e-learning.

\section{A. Location-based learning}

Learners can be located using a GPS-enabled device that supports applications and interactions that aid in locating learners. This could be made possible by programs like Mscape[11]. They can also draw existing databases location with the help of tools such as WikiMe, which is an application for iPhones and facilitates locating relevant information using GPS technology on a mobile device [4].

\section{B. Ambient Intelligence}

This is the merging of the internet of things (IoT) with high-speed communication. The Internet of things refers to the ability to assign anything on internet address hence everything can gather knowledge that will be everywhere. In mobile learning, it will possible to study everything in the surrounding that broaden individual thinking since the information is available everywhere [2].

\section{Learning Implants}

It is expected to be wearable devices would enable studying the environment. These devices will be able to be implanted in human bodies thus enable tapping into human brains giving another view of the world [8]. The wearable implants will facilitate learning by giving persons the ability to research and experiment with the environment in scales never reached or experienced before.

\section{CONCLUSION}

Cloud computing is an important aspect of technology. It has enabled users to usean array of services ranging from storing data to accessing programs via the internet. It has made mobile learning through portable and mobile devices much simpler and easier. Students can learn at their pace which was not in the case in the traditional system. Cloud computing has also reduced the cost associated with learning, and has made learning more thought-provoking; where learning can take place anywhere anytime so long as the student has access to the internet. It is hoped that by developing an animated interactive mobile learning application, which introduces the basic programming concepts to young children, this would encourage students to continue learning outside the classroom. Educational institutes are encouraged should adopt the mobile learning through cloud computing technology if the education system is to evolve. It is through this technique that different people can be involved in life-long learning in efficient, effective and time saving manner.

\section{REFERENCES}

[1] Bouyer and B. Arasteh, 'The Necessity of Using Cloud Computing in Educational System', Procedia - Social and Behavioral Sciences, vol. 143, pp. 581-585, 2014.

[2] Elamir, N. Jailani and M. Bakar, 'Framework and Architecture for Programming Education Environment as a Cloud Computing Service', Procedia Technology, vol. 11, pp. 1299-1308, 2013.

[3] J. Barnes, D. Herring, G. Nelson and C. Notar, 'Using Mobile Devices in the Classroom', in Proceedings of E-Learn: World Conference on ELearning in Corporate, Government, Healthcare, and Higher Education 2010, 1st ed., J. Sanchez and K. Zhang, Ed. Chesapeake, VA: Association for the Advancement of Computing in Education (AACE), 2010, pp. 607-609. 
[4] J. Sánchez and K. Zhang, Learning in Corporate, Government, Healthcare, and Higher Education 2010. Chesapeake, Va.: Association for the Advancement of Computing in Education, 2010.

[5] Haas, S. Caton and C. Weinhardt, 'Engineering incentives in social clouds', in Proceedings, 11th IEEE/ACM International Conference on Cluster, Cloud and Grid Computing, 1st ed., Newport Beach: IEE, 2011, pp. 572-575.

[6] Bagchi, K. Kaushik and B. Kapoor, 'Virtual labs for electronics engineering using cloud computing', 2013 3rd Interdisciplinary Engineering Design Education Conference, pp. 39-40, 2013.

[7] Sommerville, 'Teaching cloud computing: A software engineering perspective', Journal of Systems and Software, vol. 86, no. 9, pp. 2330-2332, 2013.

[8] K. Chard, K. Bubendorfer, S. Caton and O. Rana, 'Social Cloud Computing: A Vision for Socially Motivated Resource Sharing', IEEE Transactions on Services Computing, vol. 5, no. 4, pp. 551-563, 2012.

[9] L. Wang, J. Tao, M. Kunze, A. Castellanos, D. Kramer and W. Karl, 'Scientific Cloud Computing: Early Definition and Experience', 2008 10th IEEE International Conference on High-Performance Computing and Communications, vol. 825-830, 2008.

[10] M. García-Valls, T. Cucinotta and C. Lu, 'Challenges in real-time virtualization and predictable cloud computing', Journal of Systems Architecture, vol. 60, no. 9, pp. 726-740, 2014.

[11] M. Jalali, A. Bouyer, B. Arasteh and M. Moloudi, 'The Effect of Cloud Computing Technology in Personalization and Education Improvements and its Challenges', Procedia - Social and Behavioral Sciences, vol. 83, pp. 655-658, 2013.

[12] M. Parashar, M. AbdelBaky, I. Rodero and A. Devarakonda, 'Cloud Paradigms and Practices for Computational and Data-Enabled Science and Engineering', Comput. Sci. Eng., vol. 15, no. 4, pp. 10-18, 2013.

[13] S. Sazawa, M. Hashima, Y. Sato, K. Horio and K. Matsui, 'RVEC: Efficient Remote Desktop for the ENGINEERING CLOUD', 2012 26th International Conference on Advanced Information Networking and Applications Workshops, 2012.

[14] Sharples, M., Taylor, J., \& Vavoula, G. (2005). Towards a theory of mobile learning. Proceedings of mLearn 2005, 1(1), 1-9.

[15] Dong, B., Zheng, Q., Yang, J., Li, H., \& Qiao, M. (2009, July). An e-learning ecosystem based on cloud computing infrastructure. In Advanced Learning Technologies, 2009. ICALT 2009. Ninth IEEE International Conference on (pp. 125-127). IEEE. 